\title{
Sexual Dimorphism of the Electrosensory System: A Quantitative Analysis of Nerve Axons in the Dorsal Anterior Lateral Line Nerve of the Blue-Spotted Fantail Stingray (Taeniura lymma)
}

\author{
R.M. Kempster ${ }^{\text {a }}$ E. Garza-Gisholt ${ }^{a} \quad$ C.A. Egeberg ${ }^{\text {a }} \quad$ N.S. Hart ${ }^{\text {a }}$ O.R. O'Shea ${ }^{\text {b, c }}$ \\ S.P. Collin ${ }^{\text {a }}$ \\ a Oceans Institute and School of Animal Biology, The University of Western Australia, and ${ }^{b}$ Australian Institute of \\ Marine Science and Oceans Institute (MO96), Crawley, W.A., and ' Murdoch University, Murdoch, W.A., Australia
}

\section{Key Words}

Ampullae of Lorenzini · Anterior lateral line nerve .

Elasmobranch · Electrosensory system · Mate selection .

Sexual dimorphism

\begin{abstract}
Quantitative studies of sensory axons provide invaluable insights into the functional significance and relative importance of a particular sensory modality. Despite the important role electroreception plays in the behaviour of elasmobranchs, to date, there have been no studies that have assessed the number of electrosensory axons that project from the peripheral ampullae to the central nervous system (CNS). The complex arrangement and morphology of the peripheral electrosensory system has a significant influence on its function. However, it is not sufficient to base conclusions about function on the peripheral system alone. To fully appreciate the function of the electrosensory system, it is essential to also assess the neural network that connects the peripheral system to the CNS. Using stereological techniques, unbiased estimates of the total number of axons were obtained for both the electrosensory bundles exiting individual ampullary organs and those entering the CNS (via the dorsal root of the anterior lateral line nerve, ALLN) in males and females of different sizes. The dorsal root of the
\end{abstract}

ALLN consists solely of myelinated electrosensory axons and shows both ontogenetic and sexual dimorphism. In particular, females exhibit a greater abundance of electrosensory axons, which may result in improved sensitivity of the electrosensory system and may facilitate mate identification for reproduction. Also presented are detailed morphological data on the peripheral electrosensory system to allow a complete interpretation of the functional significance of the sexual dimorphism found in the ALLN.

(c) 2013 S. Karger AG, Basel

\section{Introduction}

Electroreception is an important sensory modality for many aquatic animals, and a number of studies have shown that elasmobranchs use electroreception in prey detection [Kalmijn, 1974; Kajiura and Holland, 2002; Kajiura et al., 2010; Kempster and Collin, 2011a, b; Kempster et al., 2012], predator avoidance [Sisneros and Tricas, 2002; Kempster et al., 2013], navigation [Kalmijn, 1979] and communication [Tricas et al., 1995].

The peripheral electrosensory system of elasmobranchs comprises hundreds to thousands of separate electrosensitive units known as the ampullae of Lorenzini (fig. 1) [Bullock et al., 2005]. These ampullae are tightly

\section{KARGER}

E-Mail karger@karger.com

www.karger.com/bbe
(C) 2013 S. Karger AG, Basel

0006-8977/13/0814-0226\$38.00/0
Ryan M. Kempster

School of Animal Biology, The University of Western Australia

35 Stirling Highway

Crawley, WA 6009 (Australia)

E-Mail ryankempster@supportoursharks.com 
Fig. 1. Electrosensory pore distribution map of the dorsal and ventral surfaces of T. lymma, with cluster positions and associated major canal orientations. Relative cluster size and canal lengths are highlighted. Major canals of the lateral line system are overlaid (thin grey lines). $\mathrm{H}=$ Hyoid cluster; $\mathrm{S}$ = superficial ophthalmic cluster; $\mathrm{M}=$ mandibular cluster.

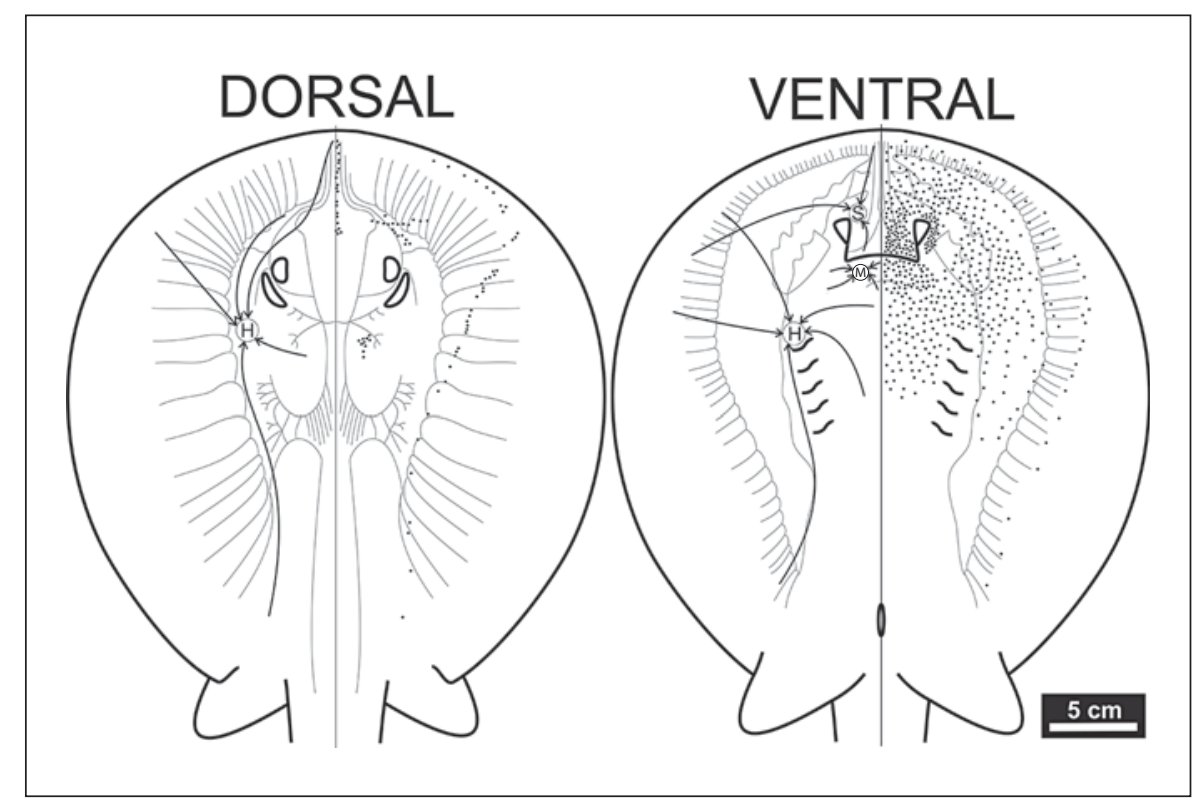

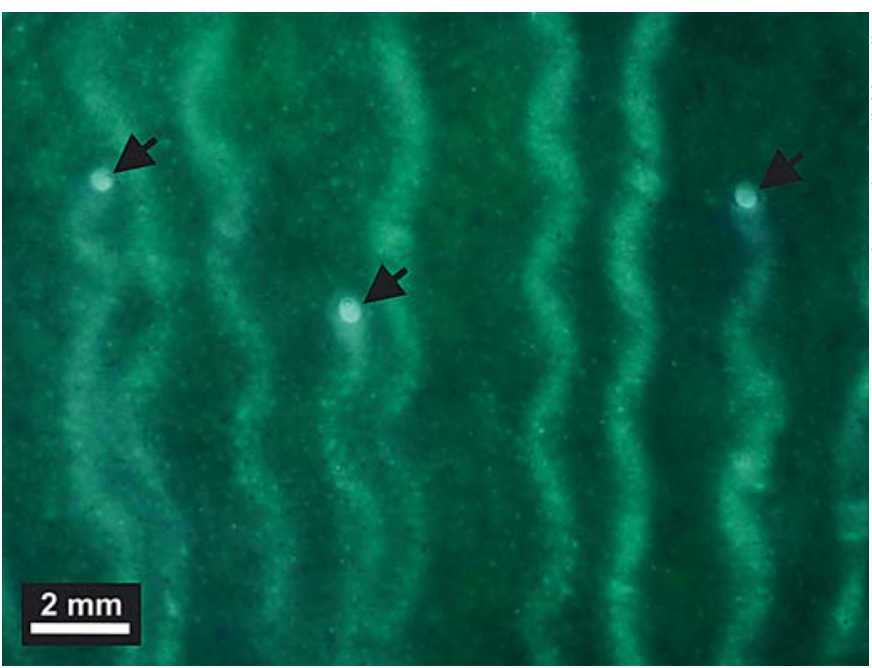

Fig. 2. T. lymma skin laid over a light box to facilitate the identification and subsequent quantification of electrosensory pores (marked with arrowheads) and their associated canals.

grouped into distinct subepidermal clusters, but each is linked to an individual pore on the surface of the body via a long, gel-filled canal (fig. 2). The complex arrangement and morphology of the peripheral electrosensory system can have a significant impact on its function [Kempster et al., 2012]. The size of pores and length of canals may be an important factor in understanding how an individual perceives, and responds to, electric fields in its environ-

Sexual Dimorphism of the Electrosensory System ment. However, it is not sufficient to base conclusions about function on the peripheral system alone.

To fully appreciate the function of the electrosensory system it is essential to assess the neural network that connects the peripheral system to the central nervous system (CNS). Within an individual ampulla, sensory receptor cells line the epithelial wall, and these cells detect the electrical potential difference between the gel-filled lumen (apical side) and the base of the receptor cell (basal side) outside the ampulla [Camperi et al., 2007]. This allows each ampulla to code minute electrical fluctuations into discharge patterns of primary afferent nerves [Murray, 1962].

Electrosensory primary afferent neurons are responsible for the detection and transduction of weak electric fields into electrical impulses, which are recognised by the CNS, to differentiate, for example, a predator over prey [Bodznick and Northcutt, 1980]. In addition, these neurons may also serve an important function in communication between sexes, due to their increased sensitivity to stimuli that vary at the same frequency as an individual's natural respiratory movements [Tricas et al., 1995]. A correlation between the frequency sensitivity of primary afferent neurones and the ventilatory signals produced by conspecifics indicates that the electrosensory system may serve an important biological function in elasmobranch social behaviours, specifically to assist with mate selection [Tricas et al., 1995].

Sexual dimorphism is a topic seldom discussed in reference to the elasmobranch electrosensory system, but may 


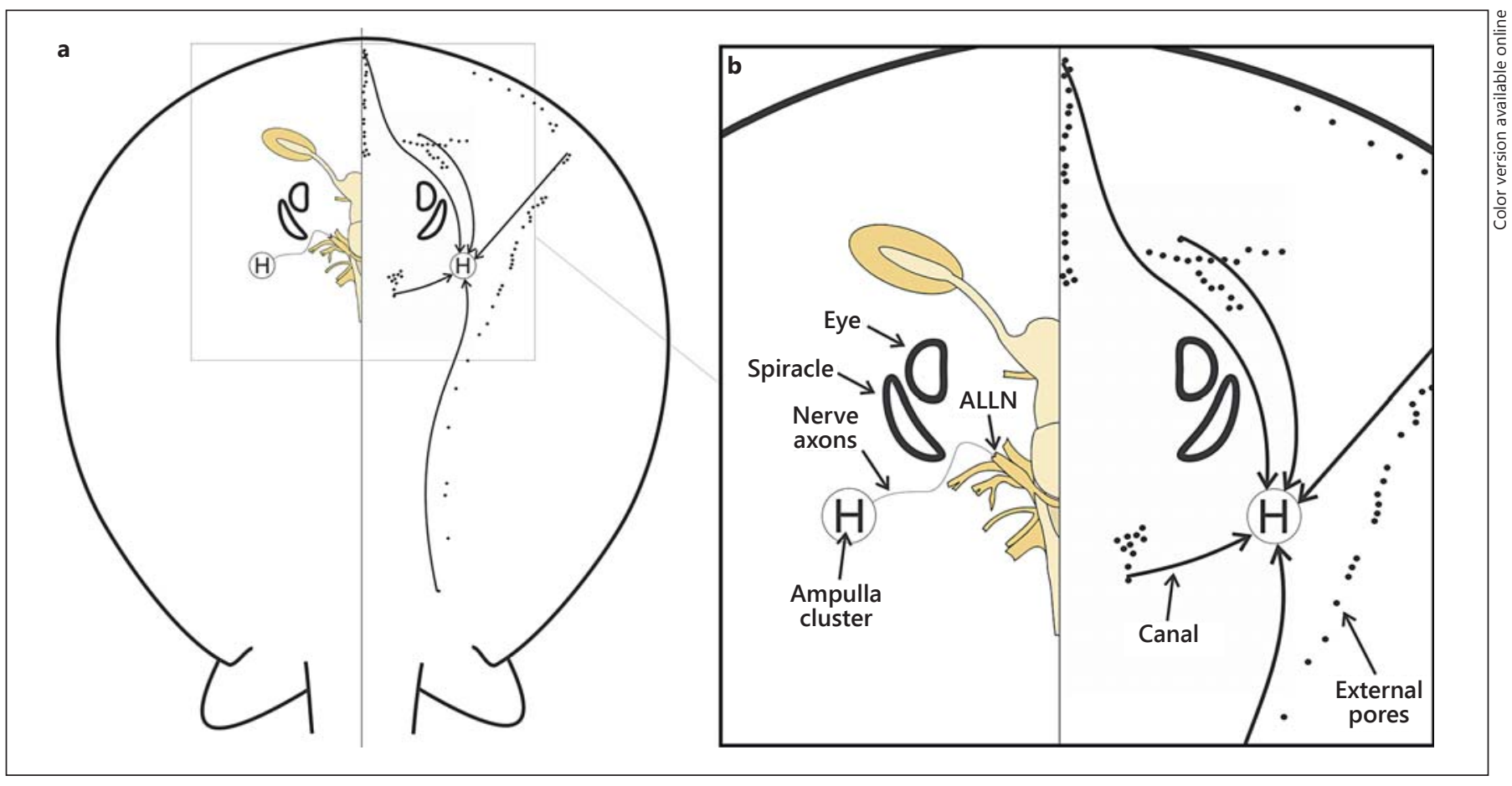

Fig. 3. Schematic diagram showing the position of the brain relative to the electrosensory network (a) of T. lymma. b Magnified view of the brain and cranial nerves. $\mathrm{H}=$ Hyoid cluster.

be an important factor in understanding communication between sexes. To date, sexual dimorphism of the electrosensory system has only been observed in the ampullae of Lorenzini of the lesser-spotted catshark, Scyliorhinus canicula [Crooks and Waring, 2013]. Variation in the structure and morphology of the ampullae was observed between males and females, which may help individuals to identify conspecifics and, thus, assist with reproductive and social behaviours [Crooks and Waring, 2013].

To better understand the origin of sexual and social behaviours in elasmobranchs, it is important to look at the neural basis of these behaviours. Unfortunately, the axons of electrosensory primary afferent nerves cofasciculate with those of mechanosensory nerves to form the anterior lateral line nerve (ALLN), making it impossible to isolate electrosensory nervous input. However, as the ALLN enters the medulla it divides into dorsal and ventral roots (fig. 3, 4). Bodznick and Northcutt [1980] presented evidence that the dorsal root consists only of electrosensory axons, and the ventral root only of mechanosensory axons, but this has not been assessed quantitatively. Moreover, to date, there have been no studies that have accurately assessed the number of sensory axons within the electrosensory system of any elas- mobranch species, despite the large variation in the number and arrangement of electrosensory pores in this group [Raschi, 1986; Kajiura et al., 2010; Kempster et al., 2012].

This investigation used stereological techniques to obtain unbiased estimates of the total number of electrosensory axons, both proximal to entering the medulla (via the dorsal root of the ALLN) and distal to the ampulla electroreceptor, to provide anatomical evidence of whether or not the dorsal root of the ALLN consists of only electrosensory axons. This investigation also revealed new insights about the relative importance of electroreception during development and between sexes; also presented are detailed morphological data on the peripheral electrosensory system to allow a complete interpretation of the functional significance of ALLN axon abundance.

\section{Materials and Methods}

\section{Ethics Statement}

This study was carried out in strict accordance with the guidelines of the Australian Code of Practice for the Care and Use of Animals for Scientific Purposes (7th ed., 2004). The protocol was approved by the Murdoch University Animal Ethics Committee (license No. U6/2010-2011; permit No. R2275/09). 
Fig. 4. Schematic diagram of the brain showing the major cranial nerves (a). b Magnified view showing the position at which the ALLN divides into dorsal and ventral roots. The asterisk indicates the position at which nerve sections of the dorsal root were cut for further analysis. PLLN = Posterior lateral line nerve.

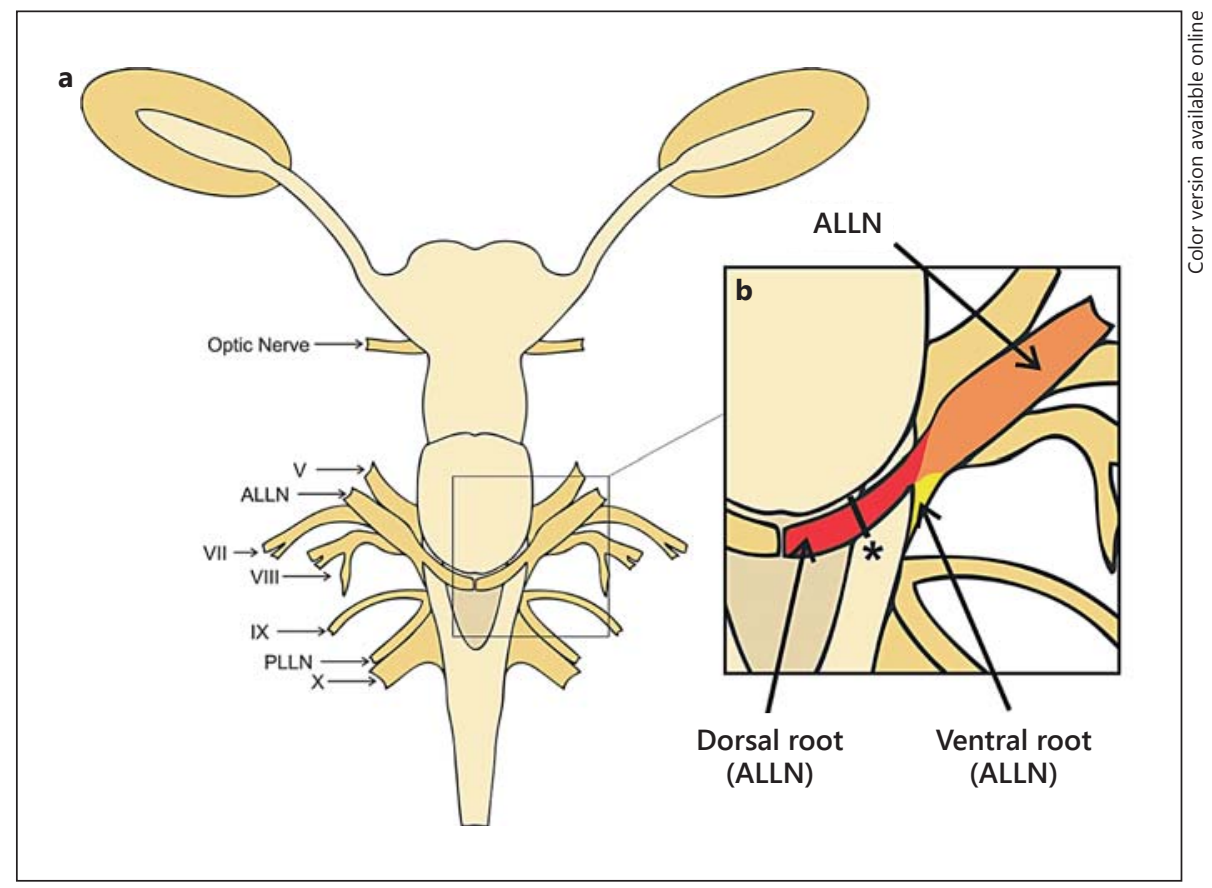

\section{Specimen Collection}

Specimens were collected in 2010 from Ningaloo Reef in Western Australia (WA fisheries exemption permit No. RS457/98-05) as part of an unrelated age, diet and growth study [O'Shea et al., 2012, 2013]. A total of 14 mature specimens ( 8 females and 6 males) of the blue-spotted fantail ray, Taeniura lymma, were used (disc width $25-32 \mathrm{~cm}$ ). Four specimens were frozen whole upon collection and later used to assess the morphology of the electrosensory system. Brains were immediately removed from 10 specimens and immersed in Karnovsky's solution (2.5\% paraformaldehyde and $4 \%$ glutaraldehyde in $0.1 \mathrm{M}$ sodium cacodylate buffer, $\mathrm{pH}$ 7.4). Ampullary clusters were also dissected from 3 specimens and immediately immersed in Karnovsky's solution.

\section{Tissue Processing}

Light and transmission electron microscopy were used for examination of cranial nerve axons at the point of innervation with individual ampullae and proximal to entering the medulla (fig. 4; ALLN dorsal root). Individual ampullae were dissected from Karnovsky-fixed tissue of the ventral hyoid, superficial ophthalmic and mandibular clusters (fig. 1). The dorsal root of the ALLN was removed from the left and right side of the brain. All dissected tissue samples were washed 3 times in $0.1 \mathrm{M}$ phosphate buffer (PB, $\mathrm{pH}$ 7.4) for $15 \mathrm{~min}$ and post-fixed in osmium tetroxide (in $50 \%$ $0.1 \mathrm{M} \mathrm{PB}, 1: 1, \mathrm{pH} 7.4$ ) for 80-120 min (depending on sample size). After a further three $15-\mathrm{min}$ rinses in $0.1 \mathrm{M} \mathrm{PB}$, samples were placed into a Lynx tissue processor. Using the automated method, samples were dehydrated through an ascending alcohol series and infiltrated with 25, 50 and 75\% Spurr epoxy resin (30 min each), followed by two changes of $100 \%$ Spurr epoxy resin ( $1 \mathrm{~h}$ each). Samples were placed in silicone moulds, filled with resin and polymerised at $60^{\circ} \mathrm{C}$ overnight. Survey sections ( $1 \mu \mathrm{m}$ in thickness) were cut with a Nova Ultratome LKB Bromma with a glass knife and stained with 3\% toluidine blue in $0.1 \mathrm{M} \mathrm{PB}$. Ultrathin sections $(\geq 100 \mathrm{~nm})$ were cut with a diamond knife, mounted on carbonstabilised colloidon grids and stained with uranyl acetate and lead citrate, according to the method of Daddow [1986]. Sections for light and electron microscopy were viewed and photographed with an Olympus $\mathrm{BH}-2$ light microscope (magnification: $\times 20-40$; fig. 5a, 6a) and a JEOL 2100 transmission electron microscope (80 $\mathrm{kV}$, magnification: $\times 1,000-2,000$; fig. $6 \mathrm{~b}$ ), respectively.

\section{Estimation of Axon Number Using Stereology}

Stained nerve sections, mounted on carbon-stabilised colloidon grids, were initially viewed on a JEOL 2100 transmission electron microscope to locate the presence of unmyelinated axons. Upon determining that no unmyelinated axons were present, additional nerve sections were processed for analysis via light microscopy.

Stained nerve sections (fig. 5a) were examined using a Nikon Optiphot-2 compound microscope with a motorised stage (MAC200; Ludl Electronic Products, USA) and a digital camera (Microfire; Optronics, USA) coupled to an IBM-PC-compatible microcomputer running a stereological analysis software package (Stereo Investigator; MicroBrightField, USA). The outline of the nerve was digitised by tracing the edges of the outermost axons (fig. 5b). Any cuts/divisions in the sample were also outlined and later subtracted from the total nerve area (fig. 5c).

The total number of nerve axons was estimated using the optical fractionator method [West et al., 1991]. As the nerve axons could be observed from a single section at low magnification $(\times 20)$, the sampling fraction was 1 [Coimbra et al., 2009]. The height of the optical dissector was considered to be the same as the thickness of the layer at all eccentricities, giving a thickness sampling fraction of 1 . The size of the counting frame used was $100 \times 100 \mu \mathrm{m}$, and the grid spacing of the systematic random grid used was $250 \times 250$ $\mu \mathrm{m}$ for all nerves examined (fig. $5 \mathrm{~b}, \mathrm{c}$ ). These stereological param- 


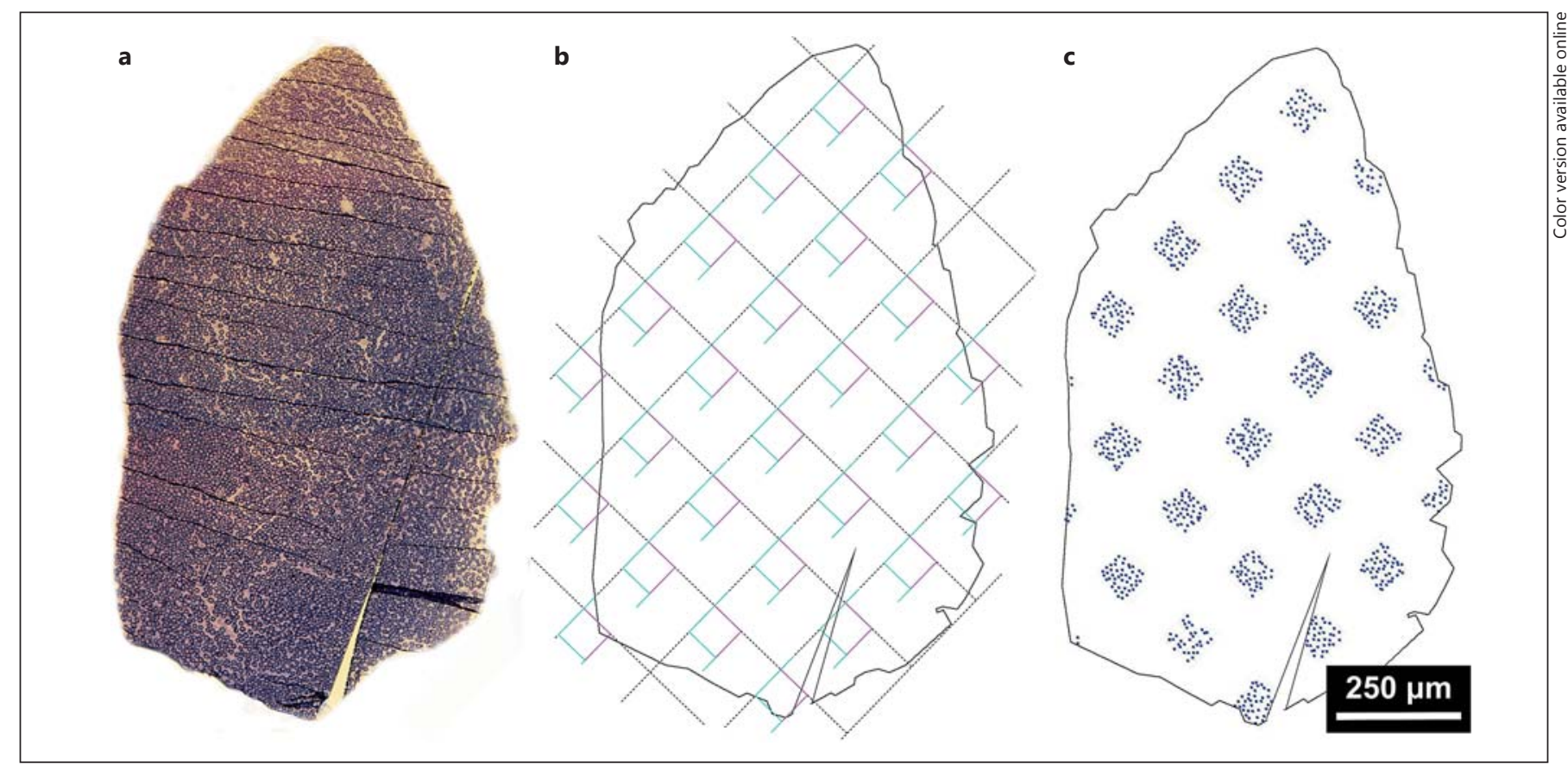

Fig. 5. Stained sections of the ALLN dorsal root of T. lymma digitised by tracing around the nerve sheath (a, b). The total number of nerve axons was estimated using the optical fractionator method [West et al., 1991]. Nerve axons were observed and counted from a single section on low magnification $(\times 20)$ with a counting frame of 100 $\times 100 \mu \mathrm{m}$ and systematic random grid spacing of $250 \times 250 \mu \mathrm{m}$ for all nerves examined $(\mathbf{b}, \mathbf{c})$.
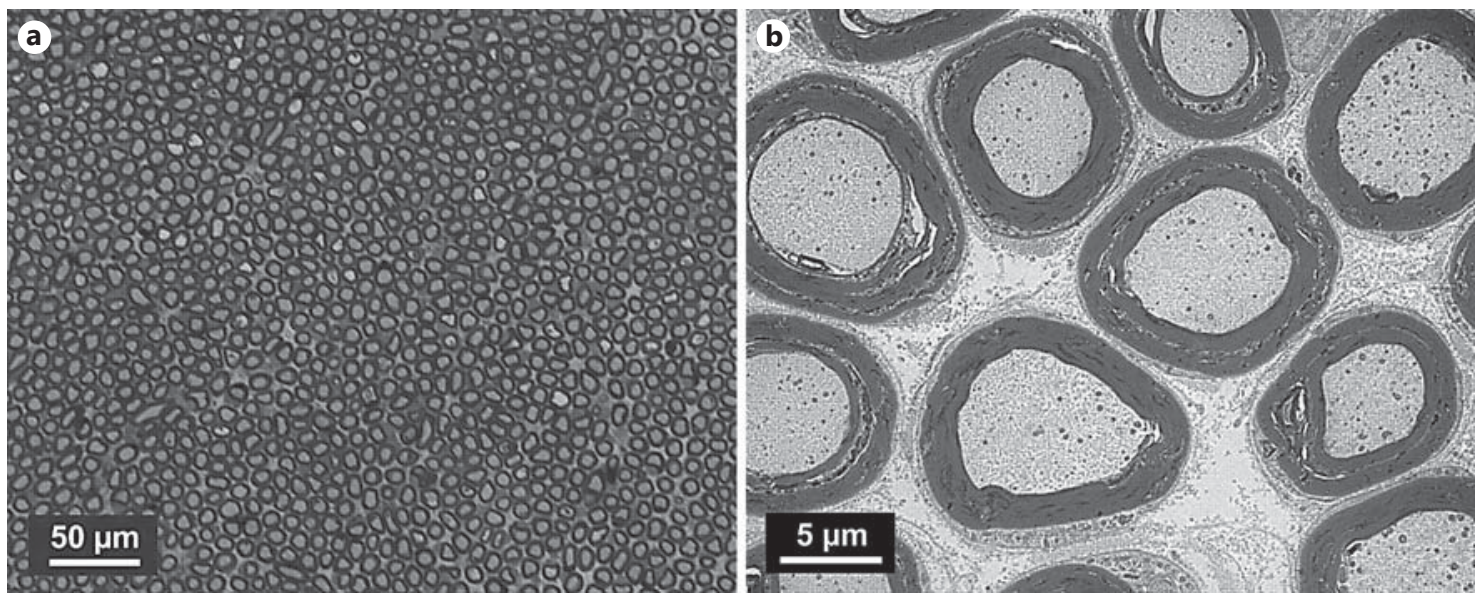

Fig. 6. Transverse section of the ALLN dorsal root of T. lymma. a Low magnification $(\times 20)$ of a light microscope section. b High magnification $(\times 1,500)$ of a transmission electron microscope section.

eters were chosen on the basis of pilot investigations (data not presented) to achieve an acceptable estimate of the coefficient of error for the ALLN in this species, which resulted in approximately 25 30 sampling sites per nerve section. We used the Schaeffer coefficient of error estimator, which is a one-stage systematic sampling procedure validated for use with the optical fractionator method
[Glaser and Wilson, 1998] used previously for sampling neurons within the retina [Coimbra et al., 2009]. A coefficient of error estimate of $<0.1$ was deemed appropriate in the present study because variance introduced by the counting process made only a small contribution to the observed group variance [Slomianka and West, 2005]. 


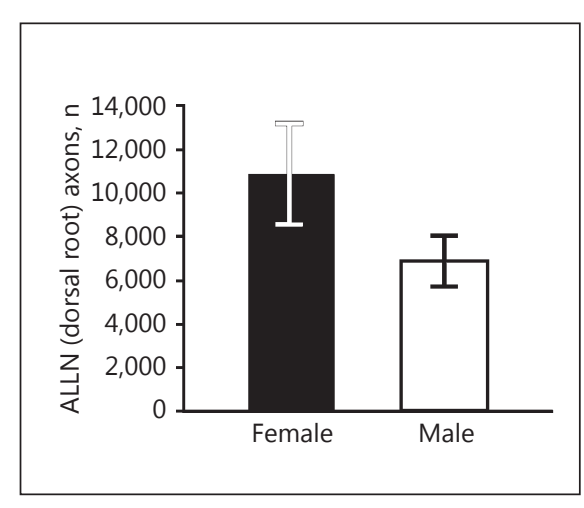

Fig. 7. Sexual dimorphism of the total number of axons in the ALLN dorsal root of T. lymma (see online suppl. table 1 for data).

\section{Distribution and Morphology of Electrosensory Ampullary}

Pores and Canals

Four individuals of T. lymma were examined for the distribution and morphology of electrosensory ampullary pores and canals. To assist in differentiating lateral line pores from electrosensory pores, a methylene blue solution (approx. $0.3 \%$ in water) was applied to the skin under slight pressure [Kempster and Collin, 2011a, b]. The solution highlighted the presence of lateral line canals leaving the electrosensory canals unchanged. The skin was then removed from the head and body, and placed on a light box to visualise the position of electrosensory pores and to facilitate accurate counting (fig. 2). The exact positions of ampullary pores were marked on a transparency placed over the skin. Canals were then traced from the pore opening to the respective ampullary cluster. Representative pore distribution maps, showing cluster location and canal association, were created using CorelDRAW ${ }^{\mathrm{TM}}$ (fig. 1). Differences in mean pore counts between individuals were statistically analysed using Minitab ${ }^{\mathrm{TM}}$. Photographs were taken of the pores and canals (fig. 2) using an Olympus SZ61 stereo microscope fitted with an Olympus DP20 camera, and the diameters of both features were measured to the nearest millimetre from the photographs using Image J.

\section{Results}

\section{Sexual Dimorphism in the Number of Electrosensory}

Nerve Axons

Electrosensory input to the CNS, via the ALLN on the left and right sides of the head, is symmetrical (as is pore distribution: fig. 1 ; two-sample $\mathrm{t}$ test: $\mathrm{t}_{15}=0.14, \mathrm{p}=$ $0.891)$. However, there is a significant sexual dimorphism (fig. 7; two-sample t test: $t_{15}=4.52, p \leq 0.001$ ) with males possessing a much lower total abundance of electrosensory nerve axons (mean 6,873 \pm SD 1,129) than females (mean 10,783 \pm SD 2,621). There is also evidence of ontogenetic variation in the electrosensory input to the CNS with females exhibiting a strong correlation with size (Pearson's correlation $=0.656, \mathrm{p}=$ 0.021 ; see online suppl. table 1; for all online suppl. material, see www.karger.com/doi/10.1159/351700). Although the same relationship was not observed in males (Pearson's correlation $=0.694, \mathrm{p}=0.056$; online suppl. table 1). It should be noted that the size range of individuals was very small (25- to $32-\mathrm{cm}$ disc width) and so further investigation is warranted.

Three major ampullary clusters were identified for $T$. lymma: the hyoid, superficial ophthalmic and mandibular clusters (fig. 1). Within each cluster, between 4 and 16 myelinated axons were observed to extend from an individual ampulla (table 1). No unmyelinated axons were observed in the electrosensory component of the ALLN (fig. 6). The number of nerve axons extending from each ampulla varied greatly between clusters (ANOVA: $F_{2}=$ 4.30, $\mathrm{p}=0.019$ ) and between individuals (ANOVA: $\mathrm{F}_{2}=$ $14.00, \mathrm{p} \leq 0.001)$ possibly indicative of ontogenetic and/ or sexual variation (table 1); however, the small sample size made it difficult to draw any firm conclusions. Within individuals, the ampullae of the mandibular cluster consistently showed a greater number of nerve axons (table 1), and no significant difference was observed between the superficial ophthalmic and the hyoid clusters (two-sample $t$ test: $\mathrm{t}_{47}=0.13, \mathrm{p}=0.896$ ).

Estimating the total number of axons per cluster, based on the mean number of axons per ampulla and the total number of ampullae per cluster, revealed that the hyoid cluster possessed the greatest total number of sensory nerve axons, with more than double that of the superficial ophthalmic cluster (table 1). The mandibular cluster had the smallest total population of nerve axons with less than half that of the superficial ophthalmic cluster (table 1).

Estimates of the total population of electrosensory nerve axons, determined by individual ampulla sections, closely match that of the total nerve population counts, determined by complete ALLN sections, proximal to entering the medulla (table 1). The continuity in total nerve axon counts from the ampullary organs to the dorsal root of the ALLN corroborate the results of Bodznick and Northcutt [1980] showing that the dorsal root consists of only electrosensory input.

\section{Distribution and Morphology of Electrosensory \\ Ampullary Pores and Canals}

T. lymma shows no intraspecific, ontogenetic (mean $1,251 \pm$ SD 15.8) or sexual dimorphism (male, mean 1,256 \pm SD 25.5; female, mean 1,247 \pm SD 3.5) in the number of 
Table 1. Observed number of nerve axons innervating individual ampullae within each subdermal cluster and an estimate of the total number of nerve axons associated with each cluster (based on the average number of axons per ampulla and the total number of ampullae per cluster)

\begin{tabular}{|c|c|c|c|c|c|c|c|c|c|}
\hline \multirow[t]{2}{*}{ Sex } & \multirow{2}{*}{$\begin{array}{l}\text { DW } \\
\mathrm{cm}\end{array}$} & \multicolumn{3}{|c|}{ Nerve axons observed, n/ampulla } & \multicolumn{4}{|c|}{ Nerve axons estimated, $\mathrm{n} /$ cluster } & \multirow{2}{*}{$\begin{array}{l}\text { Nerve } \\
\text { axons } \\
\text { observed }^{1} \text {, } \\
\text { total } \mathrm{n}\end{array}$} \\
\hline & & $\begin{array}{l}\mathrm{S} \\
(\text { mean } \pm \mathrm{SD})\end{array}$ & $\begin{array}{l}\mathrm{H} \\
(\text { mean } \pm \mathrm{SD})\end{array}$ & $\begin{array}{l}\mathrm{M} \\
(\text { mean } \pm \mathrm{SD})\end{array}$ & S & $\mathrm{H}$ & M & all clusters $^{1}$ & \\
\hline $\mathrm{F}$ & 28.5 & $\begin{array}{l}10.6 \pm 2.3 \\
(8-14)\end{array}$ & $\begin{array}{l}11.0 \pm 0.8 \\
(10-12)\end{array}$ & $\begin{array}{l}12.0 \pm 1.4 \\
(11-14)\end{array}$ & $\begin{array}{l}3,816 \\
(2,880-5,040)\end{array}$ & $\begin{array}{l}8,459 \\
(7,690-9,228)\end{array}$ & $\begin{array}{l}1,476 \\
(1,353-1,722)\end{array}$ & $\begin{array}{l}13,751 \\
(1,1923-15,990)\end{array}$ & 14,119 \\
\hline $\mathrm{F}$ & 29 & $\begin{array}{l}6.6 \pm 2.0 \\
(4-8)\end{array}$ & $\begin{array}{l}7.0 \pm 1.4 \\
(5-8)\end{array}$ & $\begin{array}{l}10.6 \pm 4.1 \\
(7-16)\end{array}$ & $\begin{array}{l}2,376 \\
(1,440-2,880)\end{array}$ & $\begin{array}{l}5,383 \\
(3,845-6,152)\end{array}$ & $\begin{array}{l}1,304 \\
(861-1,968)\end{array}$ & $\begin{array}{l}9,063 \\
(6,146-11,000)\end{array}$ & 9,488 \\
\hline M & 27 & $\begin{array}{l}6.0 \pm 0.7 \\
(5-7)\end{array}$ & $\begin{array}{l}6.2 \pm 1.1 \\
(5-8)\end{array}$ & $\begin{array}{l}8.0 \pm 1.6 \\
(6-10)\end{array}$ & $\begin{array}{l}2,160 \\
(1,800-2,520)\end{array}$ & $\begin{array}{l}4,768 \\
(3,845-6,152)\end{array}$ & $\begin{array}{l}984 \\
(738-1,230)\end{array}$ & $\begin{array}{l}7,912 \\
(6,383-9,902)\end{array}$ & 7,096 \\
\hline
\end{tabular}

Values in parentheses are min-max. Also included is an estimate of the total number of nerve axons, and the observed total number of nerve axons, associated with the dorsal root of the ALLN. $\mathrm{H}=$ Hyoid cluster; $\mathrm{S}=$ superficial ophthalmic cluster; $\mathrm{M}=$ mandibular cluster; $\mathrm{DW}=$ disc width.

${ }^{1}$ Estimates of the total population of electrosensory nerve axons, determined by individual ampulla sections, closely match that of total observed nerve population counts, determined by complete ALLN sections, proximal to entering the medulla.

pores and the location of their associated clusters (online suppl. table 2a; fig. 1).

Although there is no significant difference in the total number of electrosensory pores between individuals of $T$. lymma (online suppl. table $2 \mathrm{a}$ ), pores are not evenly distributed over the body, as significantly more pores are situated on the ventral surface (two-sample $t$ test: $t_{4}=$ $-135.82, p \leq 0.001$ ) than on the dorsal surface (online suppl. table $2 \mathrm{a}$; fig. 1 ). In addition, pores are unevenly distributed between clusters (ANOVA: $\mathrm{F}_{2}=2,075.69, \mathrm{p} \leq$ 0.001 ), with the hyoid cluster accounting for more than half of the total number of pores (online suppl. table 2a; fig. 1). The superficial ophthalmic cluster has less than half the number of pores of the hyoid cluster but more than double that of the mandibular cluster (online suppl. table 2a; fig. 1).

The width of the pores and the length of the canals in T. lymma also varies between clusters [online suppl. table $2 \mathrm{a}, \mathrm{c}$ : ANOVA (pores): $\mathrm{F}_{3}=71.36, \mathrm{p} \leq 0.001$; ANOVA (canals): $\left.F_{3}=10.02, p \leq 0.001\right]$. The largest pores and longest canals are located dorsally as part of the hyoid cluster and the smallest pores and shortest canals are located ventrally as part of the mandibular cluster (online suppl. table $2 b, c)$. However, ventrally positioned pores of the hyoid cluster are slightly smaller than those of the superficial ophthalmic cluster (online suppl. table 2b: two-sample $t$ test: $\mathrm{t}_{63}=-2.18, \mathrm{p}=0.03$ ). Canals associated with the ventral hyoid cluster are longer than those of the superficial ophthalmic cluster (online suppl. table 2c). Dorsally positioned pores of the hyoid cluster are more than double the size of the smallest pores associated with the man- dibular cluster, and canals associated with the dorsal hyoid pores are 8-10 times longer than those associated with the mandibular pores (online suppl. table 2c).

\section{Discussion}

\section{Sexual Dimorphism of Electrosensory Input to the} CNS

T. lymma's electrosensory input, via the dorsal root of the ALLN, from the left and right sides of the body, to the medulla, is symmetrical. However, there is widespread inter- and intraspecific variation within and between clusters (table 1). There is also evidence of sexual dimorphism in the total number of electrosensory nerve axons, with females having a greater number than males (fig. 7).

A greater number of electrosensory nerve axons in females may help to improve sensitivity (fig. 8). Even though the threshold sensitivity for individual sensory cells (within each ampulla) remains constant, a greater number of sensory cells may help to improve the signalto-noise ratio. Therefore, if an increase in nerve axons is an indication of increasing sensory cell number, it is highly likely that females will have an increased electrosensitivity making detection of conspecifics more accurate. However, this hypothesis should be investigated further by assessing the total number of sensory cells found in individual ampullae to determine the convergence ratio.

To date, no sexual differences have been found in the electrosensitivity of elasmobranchs during prey detection trials [Kajiura and Holland, 2002; Jordan et al., 2009], de- 
Fig. 8. Diagram showing how variation in sensitivity and resolution can alter the effectiveness of the electrosensory system. In all scenarios (a-d), 3 prey fish are present (1 large and 2 small), but depending on the rays' electrosensory capability it may only be able to detect 1 or 2 fish, and may not be able to clearly identify specific features. a Due to low resolution and low sensitivity, this ray only detects a single large unidentifiable object to the left of its head. b Due to low resolution and high sensitivity, this ray detects a large unidentified object to the left of its head and also a small unidentified object to the right of its head. c Due to high resolution and low sensitivity, this ray can only detect a single large fish to the left of its head. d Due to high resolution and high sensitivity, this ray can detect all 3 fish and can also discriminate between the large and small fish to the left of its head.

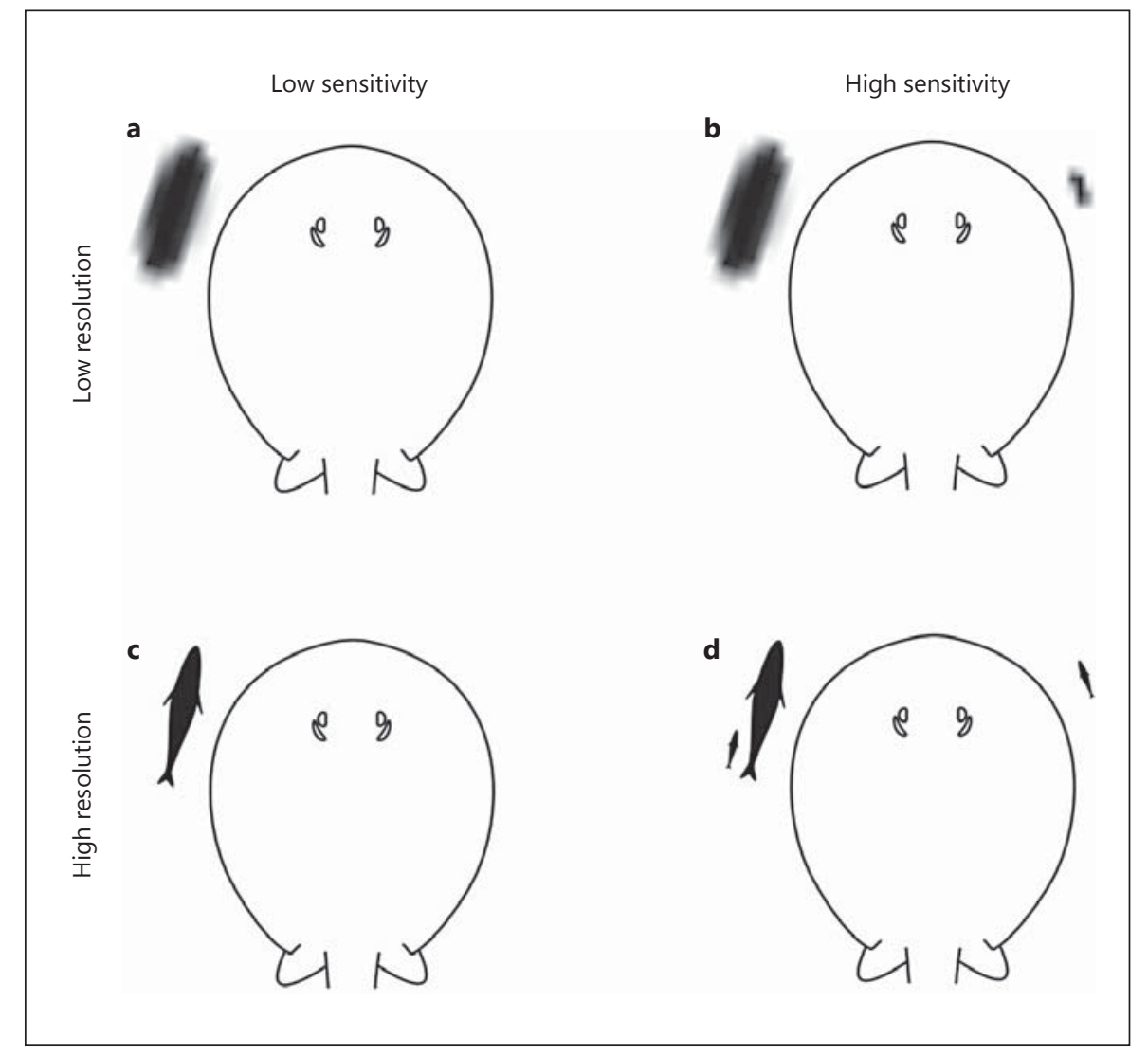

spite adult elasmobranchs typically segregating by sex [Klimley, 1987; Sims et al., 2001; Sims, 2006; RodríguezCabello et al., 2007]. Crooks and Waring [2013], however, noted sexual dimorphism in the morphology of the ampulla receptors of S. canicula, suggesting there may be behavioural differences between the sexes, specifically in the way they use the system to locate conspecifics. In addition, the use of electroreception for mate location has previously been observed in other elasmobranch species [Bratton and Ayers, 1987; Tricas et al., 1995, Sisneros and Tricas, 2002]. For example, female round stingrays (Urolophus halleri) were shown to rest on the substrate, whilst males swam in search of them, using electroreception to detect conspecifics [Sisneros and Tricas, 2002]. It is possible that individuals can locate conspecifics from their species-specific electrical output [Sisneros and Tricas, 2002]. Therefore, improved sensitivity of the electrosensory system in females may allow them to better identify suitable males for mating and be even more effective for foraging during their extended gestational period.

\section{Number of Electrosensory Nerve Axons}

The dorsal root of the ALLN of T. lymma consists only of myelinated electroreceptive sensory axons, as reported by Bodznick and Northcutt [1980]. No unmyelinated axons were identified. It is important to note that all individuals in this investigation were sexually mature, which may leave the possibility of an ontogenetic transition to complete myelination of all axons in the dorsal root of the ALLN, as has been observed in the spinal nerves of the black-tipped reef shark (Carcharhinus melanopterus) and shovelnose ray (Glaucostegus typus) [Snow et al., 1993]. However, this is highly unlikely as all the axons of the ALLN dorsal root project to the electrosensory nucleus in the medulla [Bodznick and Northcutt, 1980] and so pain-responsive unmyelinated axons are unnecessary.

The abundance of myelinated axons varies between ampullae and between clusters, with individual ampullae of the mandibular cluster having the greatest number of axons (table 1). However, as the mandibular cluster is the smallest cluster, it actually has the smallest total population of nerve axons (table 1). The function of the man- 
dibular cluster is to position the mouth for the final feeding strike [Rivera-Vicente et al., 2011]. Therefore, heightened sensory input from individual ampullae combined with a greater density of mandibular pores (fig. 1) may increase electrosensitivity and resolution (fig. 8), respectively, to improve close-range localisation of a stimulus source.

In contrast, the individual ampullae of the hyoid cluster have fewer nerve axons than those of the mandibular cluster (table 1) and are less densely distributed (fig. 1). However, given the greater total number of ampullae (online suppl. table 2a), the hyoid cluster actually accounts for more than half of all of the nerve axons within the dorsal root of the ALLN (table 1) in T. lymma. As the hyoid cluster has the greatest electrosensory input to the CNS (table 1), it likely plays an important role in the initial orientation towards prey and the detection of approaching predators.

\section{Distribution and Morphology of Electrosensory Ampullary Pores and Canals}

The distribution of ampullary electroreceptors in $T$. lymma conforms to that of other elasmobranchs, as there are no intraspecific differences in distribution between individuals [Szabo et al., 1972; Raschi, 1986; Kajiura et al., 2010; Kempster et al., 2012] (online suppl. table 2a). The majority of electrosensory pores of T. lymma are found on the ventral side of the body (associated with the hyoid cluster) and are most densely concentrated around the mouth (mandibular cluster), with very few pores located on the dorsal side (fig. 1). This arrangement is typical of batoids [Raschi, 1978; Wueringer and Tibbetts, 2008; Kempster et al., 2012], as their depressed body shape facilitates prey localisation beneath the head [Last and Stevens, 2009], and therefore a ventral concentration of pores would enhance detection of infaunal and epifaunal prey items. This suggests that, in addition to ecological constraints, electrosensory pore distribution may also be a function of body morphology.

In T. lymma, the width of electrosensory pores and the length of their canals both vary between clusters with the largest pores and longest canals positioned dorsally and associated with the hyoid cluster. The smallest pores and shortest canals are located ventrally as part of the mandibular cluster. Similar relationships have also been found in other batoid species [Rivera-Vicente et al., 2011; Camilieri-Asch et al., in press]. The presence of distinct clusters with unique characteristics, including variations in canal length and pore diameter, will likely have important functional implications [Tricas, 2001; Jordan, 2008].

\section{Conclusion}

T. lymma possesses longer canals and larger pores on its dorsal surface to facilitate the detection of a stimulus over a greater distance above the head. However, the reduced pore abundance on the dorsal surface suggests that their function is one of stimulus detection (predator avoidance) rather than stimulus source location (prey location). The densely packed somatic pores of the mandibular cluster and their associated high sensory input likely provide heightened electrosensitivity and increased resolution to improve the close range localisation of a stimulus source. In contrast, the hyoid cluster, which has a much greater electrosensory input to the CNS (table 1), longer canals (online suppl. table 2c), and the largest (online suppl. table $2 \mathrm{~b}$ ) and most widely distributed pores (fig. 1), likely plays an important role in the long-range localisation of a stimulus and mediates the initial orientation towards prey and the detection of approaching predators.

Sexual dimorphism was observed in the electrosensory system of T. lymma. Females exhibit an increased abundance of electrosensory nerve axons, resulting in a possible increase in their electrosensitivity, which will likely improve the signal-to-noise ratio, allowing females to differentiate between approaching conspecifics and potential predators. If we consider the fact that it is only the males that make the approach to waiting females for reproduction [Sisneros and Tricas, 2002], then males may not require the ability to differentiate between approaching females and predators, so any detection of an approaching stimulus could be interpreted as dangerous (predator). On the contrary, females need to be able to identify a conspecific signal over a predatory signal to facilitate mating. Thus, increased electrosensitivity, as a result of more electrosensory axons, may allow females to determine the difference between mate and predator more reliably. The fine balance between pore abundance, ampulla morphology and nervous innervation should be investigated further to assess the functional significance of these various characters.

\section{Acknowledgements}

This study was in part funded by the Australian Institute of Marine Science, and all animals were collected under W.A. fisheries exemption permit No. RS457/98-05 and Murdoch University Animal Ethics licence No. U6/2010-2011, Murdoch University ethics permit No. R2275/09. The work was also supported by funding from the W.A. State Government and The University of Western Australia (to S.P.C.). The authors wish to thank the Depart- 
ment of Environment and Conservation (W.A.) and field volunteers Thomas Hill, Kim Brooks, Thomas Espeland and Mark Meekan. A special thanks goes to Joao Paulo Coimbra for sharing valuable knowledge on the use of stereological imaging and for his continued support and guidance. The authors also acknowledge the facilities, and the scientific and technical assistance of the $\mathrm{Na}$ - tional Imaging Facility at the Centre for Microscopy, Characterisation and Analysis, The University of Western Australia, a facility funded by the University, State and Commonwealth Governments. Finally, the authors thank Caroline Kerr for her invaluable guidance and support throughout this work.

\section{References}

Bodznick D, Northcutt R (1980): Segregation of electro- and mechanoreceptive inputs to the elasmobranch medulla. Brain Res 195:313-321.

Bratton BO, Ayers JL (1987): Observations on the electric organ discharge of two skate species (Chondrichthyes: Rajidae) and its relationship to behavior. Environ Biol Fish 20:241254.

Bullock T, Hopkins C, Popper A, Fay R (2005): Electroreception. Springer Handbook of Auditory Research. New York, Springer.

Camilieri-Asch V, Kempster RM, Collin SP, Johnstone R, Theiss SM (in press): A comparison of the electrosensory morphology of a euryhaline and a marine stingray. Zoology.

Camperi M, Tricas TC, Brown BR (2007): From morphology to neural information: the electric sense of the skate. Plos Comput Biol 3: 1083-1096.

Coimbra JP, Trévia N, Videira Marceliano ML, da Silveira Andrade-Da-Costa BL, Picanço-Diniz CW, Yamada ES (2009): Number and distribution of neurons in the retinal ganglion cell layer in relation to foraging behaviors of tyrant flycatchers. J Comp Neurol 514:66-73.

Crooks N, Waring C (2013): A study into the sexual dimorphisms of the ampullae of Lorenzini in the lesser-spotted catshark, Scyliorhinus canicula (Linnaeus, 1758). Environ Biol Fish 96:585-590

Daddow LYM (1986): An abbreviated method of the double lead stain technique. J Submicrosc Cytol 18:221-224.

Glaser EM, Wilson PD (1998): The coefficient of error of optical fractionators population size estimates: a computer simulation comparing three estimators. J Microsc 192:163-171.

-Jordan L (2008): Comparative morphology of stingray lateral line canal and electrosensory systems. J Morphol 269:1325-1339.

-Jordan L, Kajiura S, Gordon M (2009): Functional consequences of structural differences in stingray sensory systems. Part II: electrosensory system. J Exp Biol 212:3044-3050.

Kajiura S, Holland K (2002): Electroreception in juvenile scalloped hammerhead and sandbar sharks. J Exp Biol 205:3609-3621.

-Kajiura S, Cornett A, Yopak K (2010): Sensory Adaptations to the environment: electroreceptors as a case study; in Carrier J, Heithaus M, Musick J (eds): Sharks and Their Relatives: Physiological Adaptations, Behavior, Ecology, Conservation, and Management. London, CRC Press, pp 393-433.
Kalmijn A (1974): The detection of electric fields from inanimate and animate sources other than electric organs; in Fessard A (ed): Handbook of Sensory Physiology. Berlin, Springer, pp 147-200.

Kalmijn A (1979): Experimental evidence of geomagnetic orientation in elasmobranch fishes. Woods Hole, Oceanographic Institution.

Kempster RM, Collin SP (2011a): Electrosensory pore distribution and feeding in the megamouth shark Megachasma pelagios (Lamniformes: Megachasmidae). Aquat Biol 11:225228.

Kempster RM, Collin SP (2011b): Electrosensory pore distribution and feeding in the basking shark Cetorhinus maximus (Lamniformes: Cetorhinidae). Aquat Biol 12:33-36.

Kempster RM, McCarthy ID, Collin SP (2012): Phylogenetic and ecological factors influencing the number and distribution of electroreceptors in elasmobranchs. J Fish Biol 80: 2055-2088.

Kempster RM, Hart NS, Collin SP (2013): Survival of the stillest: predator avoidance in shark embryos. PLoS One 8:e52551.

Klimley AP (1987): The determinants of sexual segregation in the scalloped hammerhead shark Sphyrna lewini. Environ Biol Fish 18: 27-40.

Last PR, Stevens JD (2009): Sharks and Rays of Australia. London, Havard University Press.

Murray RW (1962): The response of the ampullae of Lorenzini of elasmobranchs to electrical stimulation. J Exp Biol 39:119-128.

O'Shea OR, Meekan MG, van Keulen M (2012): Lethal sampling of stingrays (Dasyatidae) for research. In: ANZCCART Conference 2012 Thinking Outside the Cage: A Different Point of View, 24-26 July, Perth, Western Australia.

O'Shea OR, Thums M, Keulen M, Kempster RM, Meekan M (2013): Dietary partitioning by five sympatric stingrays (Dasyatidae) at Ningaloo Reef, Western Australia. J Fish Biol http://onlinelibrary.wiley.com/doi/10.1111/ jfb.12104/abstract.

Raschi W (1978): Notes on the gross functional morphology of the ampullary system in two similar species of skates, Raja erinacea and $R$. ocellata. Copeia 1978:48-53.

Raschi W (1986): A morphological analysis of the ampullae of Lorenzini in selected skates (Pisces, Rajoidei). J Morphol 189:225-247.
Rivera-Vicente AC, Sewell J, Tricas TC (2011): Electrosensitive spatial vectors in elasmobranch fishes: implications for source localization. PLoS One 6:e16008.

Rodríguez-Cabello C, Sánchez F, Olaso I (2007) Distribution patterns and sexual segregations of Scyliorhinus canicula (L.) in the Cantabrian Sea. J Fish Biol 70:1568-1586.

Sims DW (2006): Differences in habitat selection and reproductive strategies of male and female sharks; in Ruckstuhl KE, Neuhaus P (eds): Sexual Segregation of the Vertebrates: Ecology of the Two Sexes. Cambridge, Cambridge University Press, pp 127-147.

Sims DW, Nash JP, Morritt D (2001): Movements and activity of male and female dogfish in a tidal sea lough: alternative behavioural strategies and apparent sexual segregation. Mar Biol 139:1165-1175.

Sisneros JA, Tricas TC (2002): Neuroethology and life history adaptations of the elasmobranch electric sense. J. Physiol Paris 96:379389.

Slomianka L, West MJ (2005): Estimators of the precision of stereological estimates: an example based on the CA1 pyramidal cell layer of rats. Neuroscience 136:757-767.

- Snow PJ, Plenderleith MB, Wright LL (1993): Quantitative study of primary sensory neurone populations of three species of elasmobranch fish. J Comp Neurol 334:97-103.

Szabo T, Kalmijn A, Enger P, Bullock T (1972): Microampullary organs and a submandibular sense organ in the fresh water ray, Potamotrygon. J Comp Physiol A 79:15-27.

Tricas T (2001): The neuroecology of the elasmobranch electrosensory world: why peripheral morphology shapes behavior. Environ Biol Fish 60:77-92.

Tricas TC, Michael SW, Sisneros JA (1995): Electrosensory optimization to conspecific phasic signals for mating. Neurosci Lett 202:129132.

West MJ, Slomianka L, Gundersen HJG (1991): Unbiased stereological estimation of the total number of neurons in the subdivisions of the rat hippocampus using the optical fractionator. Anat Rec 231:182-497.

$\checkmark$ Wueringer BE, Tibbetts IR (2008): Comparison of the lateral line and ampullary systems of two species of shovelnose ray. Rev Fish Biol Fish $18: 47-64$. 